The Journal of Laryngology \& Otology

http://journals.cambridge.org/JLO

Additional services for The Journal of Laryngology \& Otology:

Email alerts: $\underline{\text { Click here }}$

Subscriptions: $\underline{\text { Click here }}$

Commercial reprints: $\underline{\text { Click here }}$

Terms of use : $\underline{\text { Click here }}$

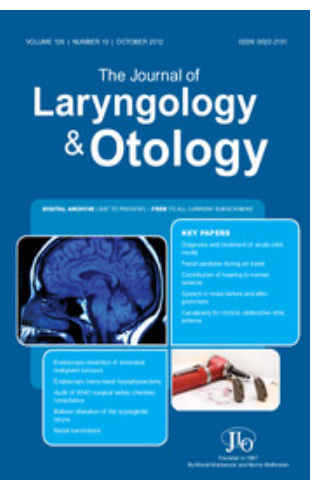

\title{
Craniometaphyseal and craniodiaphyseal dysplasia, head and neck manifestations and management
}

Aurelia Richards, Caroline Brain, M. J. Dillon and C. M. Bailey

The Journal of Laryngology \& Otology / Volume 110 / Issue 04 / April 1996, pp 328 - 338

DOI: 10.1017/S0022215100133560, Published online: 29 June 2007

Link to this article: http://journals.cambridge.org/abstract_S0022215100133560

How to cite this article:

Aurelia Richards, Caroline Brain, M. J. Dillon and C. M. Bailey (1996). Craniometaphyseal and craniodiaphyseal dysplasia, head and neck manifestations and management. The Journal of Laryngology \& Otology, 110, pp 328-338 doi:10.1017/ S0022215100133560

Request Permissions : $\underline{\text { Click here }}$ 


\title{
Craniometaphyseal and craniodiaphyseal dysplasia, head and neck manifestations and management
}

\author{
Aurelia Richards, F.R.C.S., Caroline Brain, M.D., M.R.C.P.*, M. J. Dillon, F.R.C.P.*, \\ C. M. BAILEY, B.SC., F.R.C.S.
}

\begin{abstract}
Craniometaphyseal and craniodiaphyseal dysplasia are rare genetic disorders of bone due to modelling errors of long bones and skull bones. These syndromes present with multiple ENT symptomatology from an early age. The diagnostic distinction can now be made radiologically by serial skeletal survey which is important for prognosis. We review the clinical, radiological, computed tomography (CT) scan, otological, audiological and histopathological findings in two cases with craniodiaphyseal, and two cases with craniometaphyseal dysplasia, and report our experiences of medical and surgical treatment to date.

In the craniodiaphyseal dysplasia, the hearing abnormality progressed from an initial conductive to a mixed loss on serial audiometric follow up. Temporal bone CT scans showed narrowing of the middle ear cavity, internal auditory meatus, and facial nerve canal at the geniculate ganglion. Benefits from choanal stenosis surgery, craniofacial remodelling and dacrocystorhinostomy were shortlived. Calcitriol therapy with a low calcium diet did not alter the clinical course of progression in our cases. The underlying defect, causing net bone formation in these phenotypically similar syndromes, appears to be different when based on the differing biochemical responses to calcitriol and bone biopsy findings. Increased numbers of osteoblasts were found in bone biopsies from both cases with craniodiaphyseal dysplasia.

Early recognition is crucial in these conditions as therapy directed at the underlying bony defect has the best chance of success if initiated in infancy (Cole et al., 1988; Fanconi et al., 1988; Key et al., 1988).
\end{abstract}

Key words: Craniometaphyseal dysplasia; Craniodiaphyseal dysplasia; Deafness; Choanal atresia; Nasal obstruction; Facial palsy; Osteoblast; Calcitriol

\section{Introduction}

Craniotubular dysplasias morphologically share various degrees of cranial dysplasia and tubular modelling defects. In a comprehensive review, Gorlin and colleagues (1969) divided craniotubular dysplasias into Pyle's disease, autosomal dominant and recessive craniometaphyseal dysplasia, craniodiaphyseal dysplasia, frontometaphyseal dysplasia, SchwarzLelek syndrome, dysosteosclerosis and oculodentosseous dysplasia.

Craniometaphyseal dysplasia (CMD) is the term coined by Jackson et al., in 1954 for a hereditary bone disease with: (1) metaphyseal widening of the tubular bones, and (2) bony overgrowth of the facial and skull bones (leontiasis ossea). Joseph et al., first used the term craniodiaphyseal dysplasia (CDD) in 1958 to describe a rare bone dysplasia characterized by massive craniofacial hyperostosis and sclerosis associated with the tubular bones radiologically having the shape of a policeman's truncheon with diaphyseal endostosis without metaphyseal flare.
In both these dysplasias, there is progression of facial and cranial bony thickening, distortion and enlargement causing typical facies with frontal and paranasal bossing, a broad flat nasal bridge with a saddle deformity, nasal obstruction, paranasal sinus and mastoid obliteration, hypertelorism, dental malocclusion and lacrimal duct obstruction. Bony compression of cranial nerves II, III, VI, VII and VIII results in strabismus, facial nerve palsy, deafness and blindness. Eventually death from narrowing of the foramen magnum and compression of the medulla may occur in CDD and severe forms of CMD (Munro et al., 1983). The differential diagnosis of CMD has been reviewed extensively (Jackson et al., 1954; Rubin, 1964; Millard et al., 1967; Gorlin et al., 1969) and is important as natural progression and prognosis is worse in CDD. The diagnosis of CMD or $\mathrm{CDD}$ is principally radiological through serial skeletal surveys (Table I) (Shafer et al., 1990 unpublished). CDD is one of the rarest of the sclerosing bone dysplasias with fewer than 20 reported cases (Levy and Kozlowski, 1987; Gorlin

From the Departments of Otolaryngology and Medicine*, Great Ormond Street Hospital for Children NHS Trust, London, UK. Presented at the British Association of Paediatric Otolaryngologists meeting. October 1994, London. Accepted for publication: 31 December 1995. 
TABLE I

RADIOLOGICAL FEATURES OF CMD AND CDD

Skull vault, base, maxillae and mandible:

CDD:Moderate sclerosis and overgrowth of the cranial vault, base, maxilla, and mandible by seven months of age. Progressive massive hyperostosis and overgrowth of all cranial and facial bones by two years of age with subsequent progression encroaching upon optic and cranial nerve foramina.

CMD:Early sclerosis and overgrowth of the maxilla, cranial base and mandible. Recession of the disease process after two years such that by five years sclerosis is much less dense and the supraorbital rims are nearly normal.

\section{Ribs and clavicle:}

CDD:Progressive marked sclerosis and widening of the ribs with obliteration of the medullary cavity by seven months of age. Midclavicular sclerosis, hyperostosis and widening by three months sparing the manubrial and acromial ends becoming more overgrown by five years.

CMD:Initially ribs are markedly sclerotic but not widened, becoming widened but nonsclerotic with patent medullary cavities by five years. Midclavicular sclerosis, hyperostosis and widening by three months which resolves to become normal by five years of age.

\section{Long bones:}

CDD:Progressive straightening of long bones by diaphyseal widening ("Policeman's truncheon" appearance) occurring by the age of two years becoming more pronounced by five years. Progressive straightening of the humerus.

CMD:Minimal or no diaphyseal sclerosis and a normal calibre cortex of the long bones but marked metaphyseal flare "Erhlenmeyer flask" appearance by five years of age. Normal upper limb bones by five years.

Hands, pelvis and vertebra:

CDD:Bullet-shaped phalanges by two years of age Progressive uniform sclerosis of the vertebra, narrowed pelvic inlet and narrowed overgrown iliac wings by two years of age.

CMD:Normal hand, pelvis and spine by five years of age.

et al., 1990). Martin found 48 reported cases of CMD in 1978. The genetic basis has not yet been identified for CMD or CDD. Inheritance in CDD is likely to be autosomal recessive. CMD is more often inherited as an autosomal dominant trait rather than by recessive transmission (Gorlin et al., 1990). The exact pathogenesis is not known for either of these syndromes. The general impression is that there is normal peripheral calcium metabolism in CMD and CDD (Macpherson, 1974; Kaitila et al., 1975; Martin, 1978; Gorlin et al., 1990). Net bone formation is thought to result from a defect in bone resorption (underactive osteoclasts) and/or formation (overactive osteoblasts) (Greenspan, 1991). The findings from the few bone biopsy reports in the literature are inconsistent. An increased number of osteoblasts were described in early histopathological reports (Halliday, 1949; Jackson et al., 1954). Later reports found no osteoclasts in the endosteal or periosteal layers (Millard et al., 1967), defective calcification of bone matrix with enhancement of bone volume (Bonucci et al., 1977), an enlarged osteoclastic surface area with elevated numbers of osteoclasts (Key et al., 1988) and that both bone formation and resorption was high (Fanconi et al., 1988). Recent research has found that bone marrow-derived osteoclast-like cells from a patient with CMD lack expression of osteoclast-reactive vacuolar proton pumps (Yamamoto et al., 1993).

Ear or nasal complaints are the presenting symptoms in two thirds of cases and some secondary or associated otological or nasal symptom is present in three quarters of cases with CMD (Martin, 1978). Otorhinological complaints are reported in all cases of CDD (Levy and Kozlowski, 1987; Gorlin et al., 1990). How best to manage the complex ENT symptomatology that these rare syndromes present has evolved with an improved understanding of the natural history of these conditions and is illustrated by the following case histories.

\section{Case histories}

Case 1

A seven-week-old Caucasian girl was referred to the Otolaryngology department with a history of being snuffly since birth with difficulties in feeding. A choanal stenosis involving the vomer was found, drilled and dilated to $18 \mathrm{FG}$ and the vomer removed. Re-obstruction of the single common posterior choanal opening by bone occurred within one year when a mild left lower motor neurone VIIth nerve palsy, and otitis media with effusion were noted also. Left epiphora became a problem at six months of age. A dacryocystorhinostomy (DCR) was performed at 18 months of age for recurrent dacrocystitis with great difficulty due to the grossly thickened $1 / 2$ centimetre ivory-hard cortical bone. No abnormality was noted in the bone chips sent for histology at this time. She remained symptom-free after the DCR for five months. Over 18 months her facial appearance became markedly abnormal with the typical broad nasal bridge, hypertelorism, paranasal bossing and a head circumference above the 97th centile (Figure 1a). The diagnosis of craniodiaphyseal dysplasia was made on skeletal survey (Figures 1b, $1 \mathrm{c}$ and 1d). Hearing was assessed by early auditory brainstem response testing and language milestones were normal. At the age of two, bilateral grommets were inserted. The posterior halves of both tympanic membranes were retracted and collapsed onto the promontory with serous fluid anteriorly. At two and a half years of age a deterioration in hearing was noticed by her mother. Conditioned free-field and bone-conduction audiometry showed a bilateral complete conductive hearing loss (Figure 2). A CT scan of the temporal bones was performed (Figures $1 \mathrm{e}$ and 1f). At the age of three, she commenced a calcitriol and a low calcium diet. A revision DCR with a huge rhinostomy was performed at the age of three and a half years. The bone was found to be $2 \mathrm{~cm}$ thick. Restenosis occurred after four months. At four years her left VIIth nerve weakness progressed to a complete palsy. This was treated with a short, high-dose course of prednisolone with improvement for two months. However, the VIIth nerve palsy recurred and became permanent despite continued prednisolone over the next four months. Her serum alkaline phosphatase was markedly elevated throughout her clinical course, unaffected by the calcitriol and low calcium diet. All other 


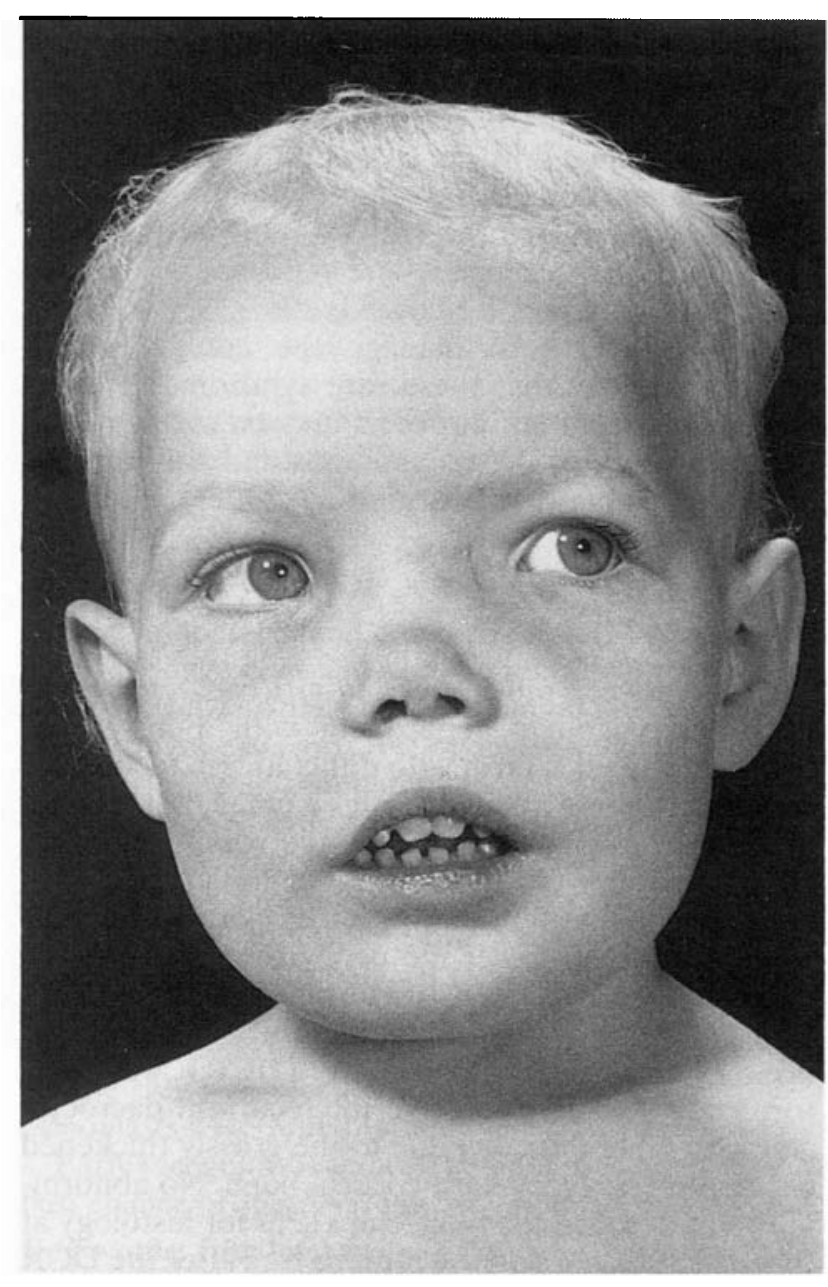

(a)

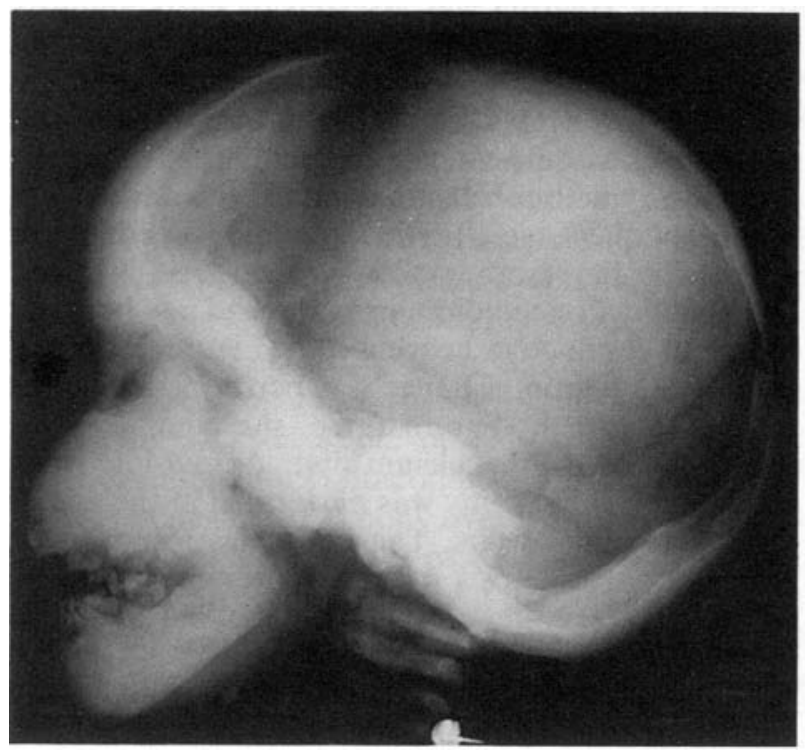

(b)

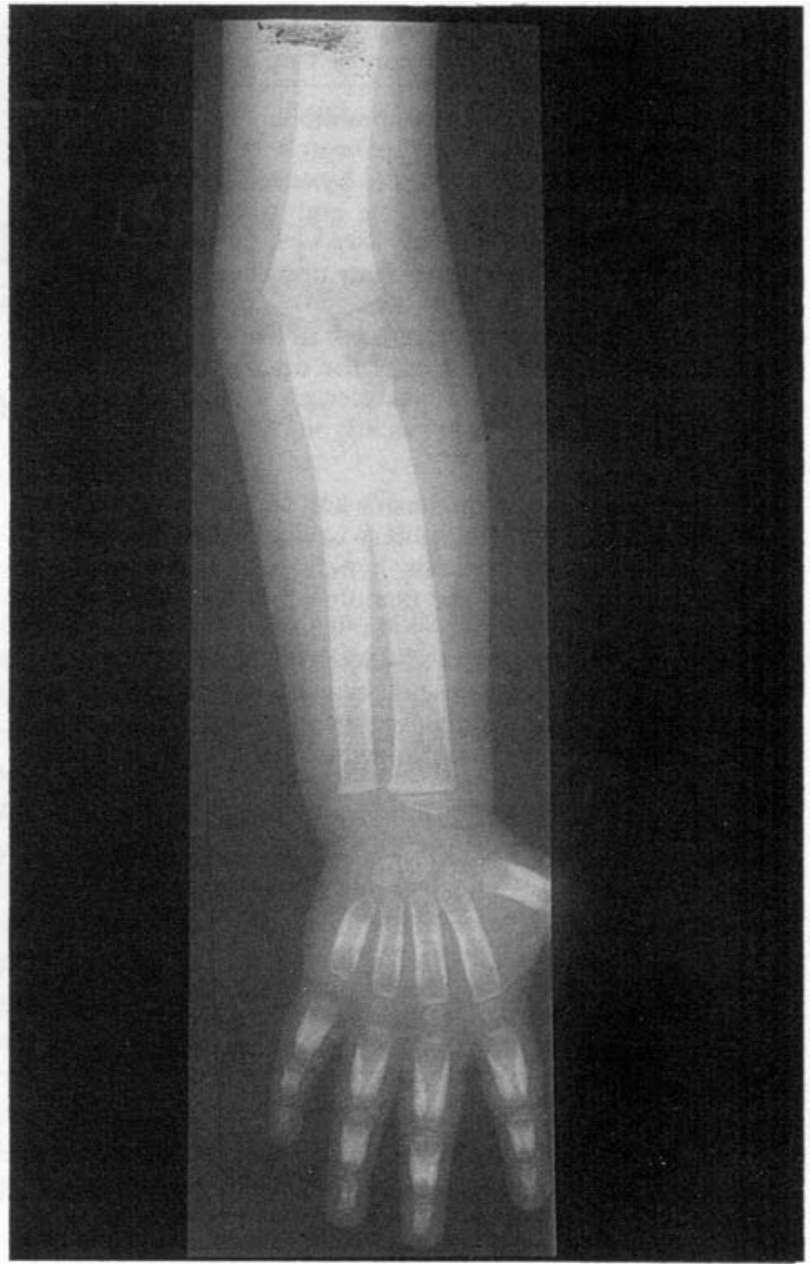

(c)

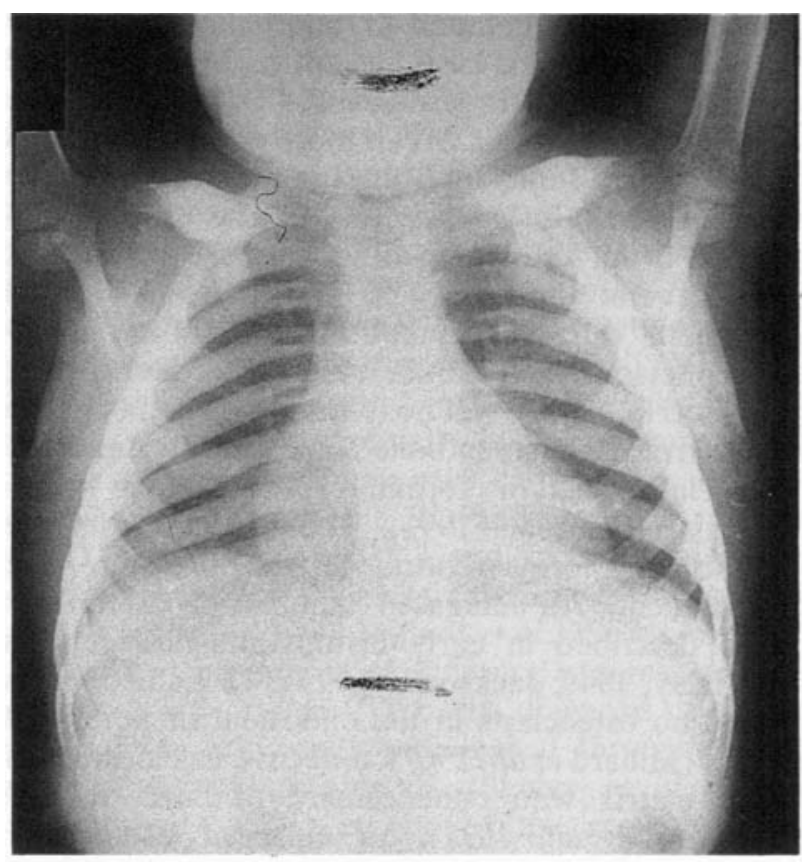

(d)

FIG. 1

Case 1 Age two and a half years (a) Facial appearance (b) Plain skull X-ray (c) Plain X-ray of radius, ulna and bullet-shaped phalanges. (d) Plain chest $\mathrm{X}$-ray-note midclavicular hyperostosis and widened ribs. 


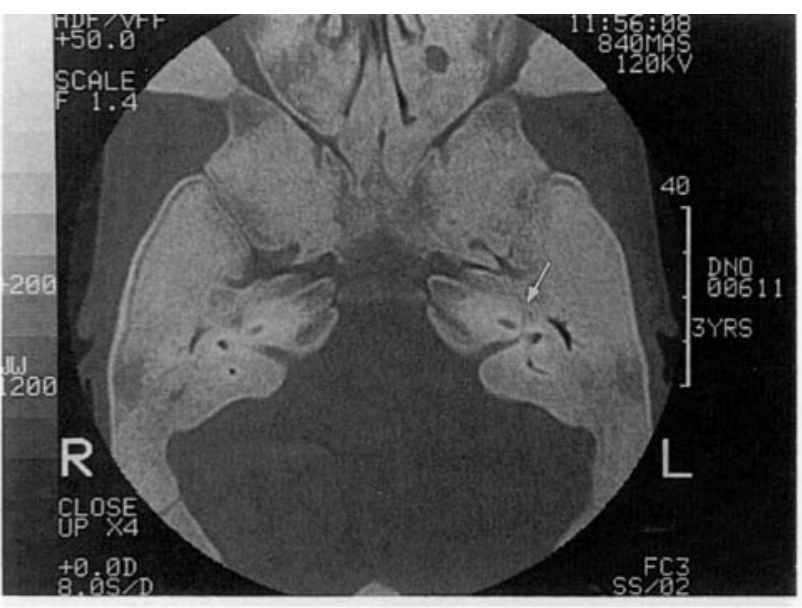

(e)

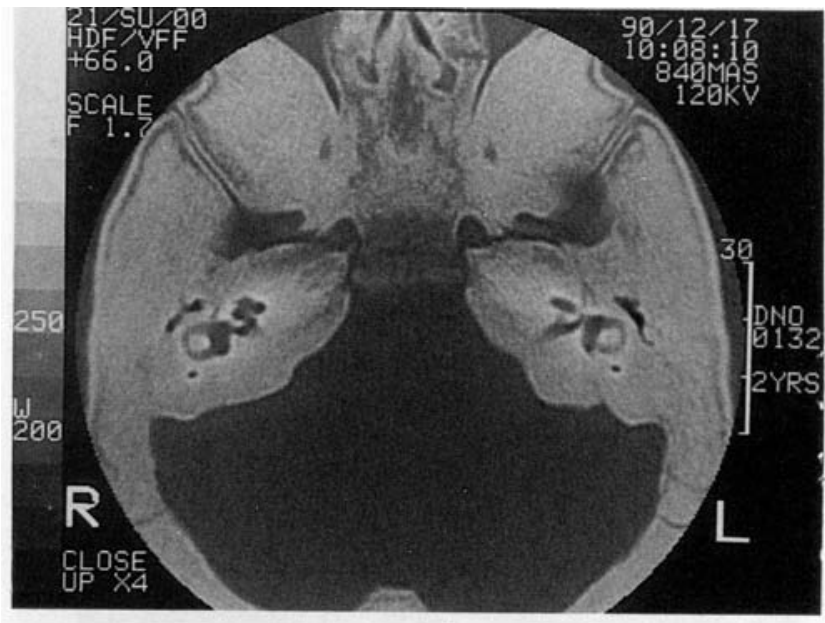

(f)

FIG. 1

Case 1 (e \& f) CT scans (1991) of the temporal bones. In (e) the white arrow points to narrowing of the VIIth nerve by bone at the geniculate ganglion and the second part of the intratympanic VIIth nerve. The middle ear cavities are markedly reduced. In (f) the labyrinths appear normal and unaffected.

serum and urine biochemistry was normal. Recently, her vision and visual evoked response conduction times in the left eye have deteriorated. After two years on calcitriol and a low calcium diet, with no evidence of arrested progression of bone formation, this therapy has been discontinued and treatment aimed at osteoblast suppression has been substituted.

\section{Case 2}

This second child of Indian and West African parents had a left LMN facial palsy at birth which became bilateral by 10 days of age. He presented at

\section{AIGHT EAR}

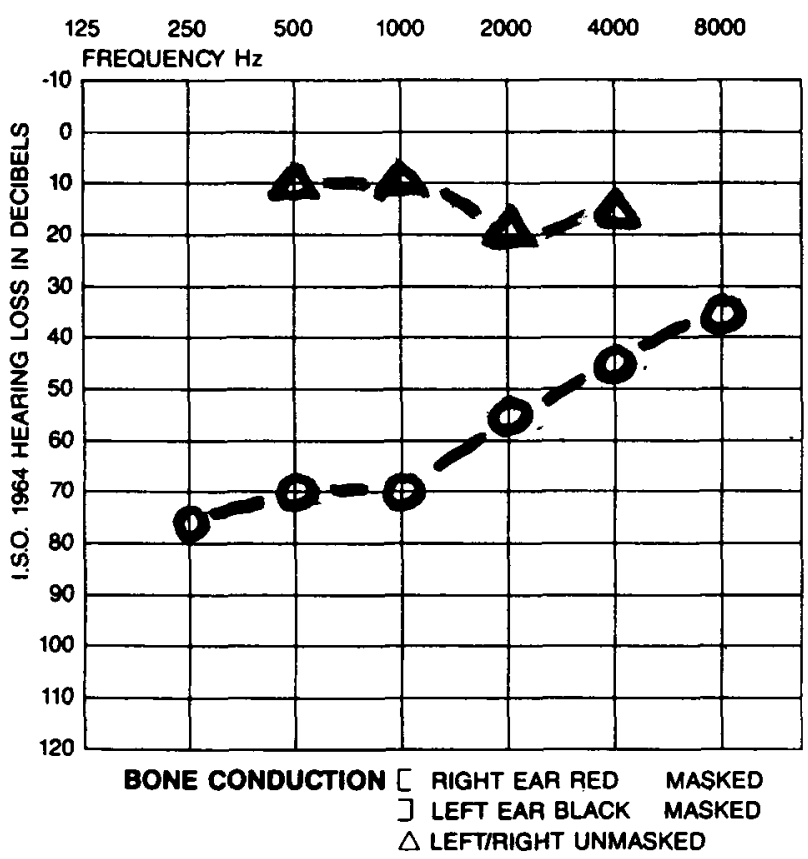

three months with a six-week history of nasal obstruction and feeding difficulties. Incomplete choanal stenosis was present. Flattening of the nasal bridge and mild hypertelorism could be recognized (Figure 3a). His head circumference was greater than the 90 th centile. He was unable to smile or close his eyes fully due to his bilateral facial palsy. Skeletal survey found changes consistent with craniodiaphyseal dysplasia (Figures $3 b, 3 c$ and $3 d$ ). Eye movements and visual evoked responses were normal. Facial nerve electromyography showed partial function in all areas to stimulation. Auditory brainstem response testing revealed a mixed bilateral hearing loss of moderate severity. At one year of

\section{LEFT EAR}

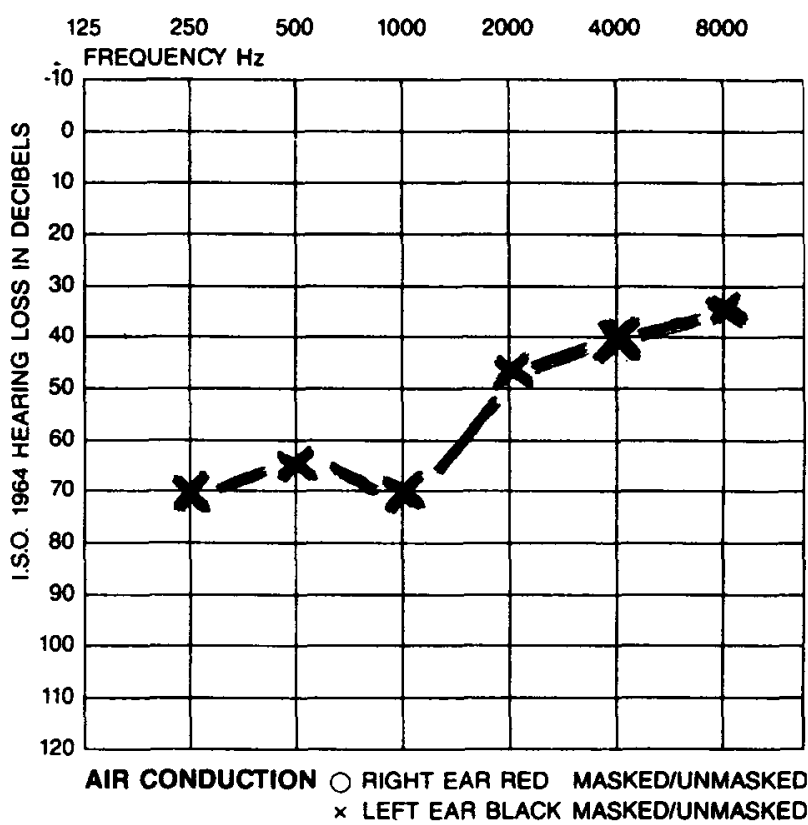

FIG. 2

Audiogram Case 1 (1991). 


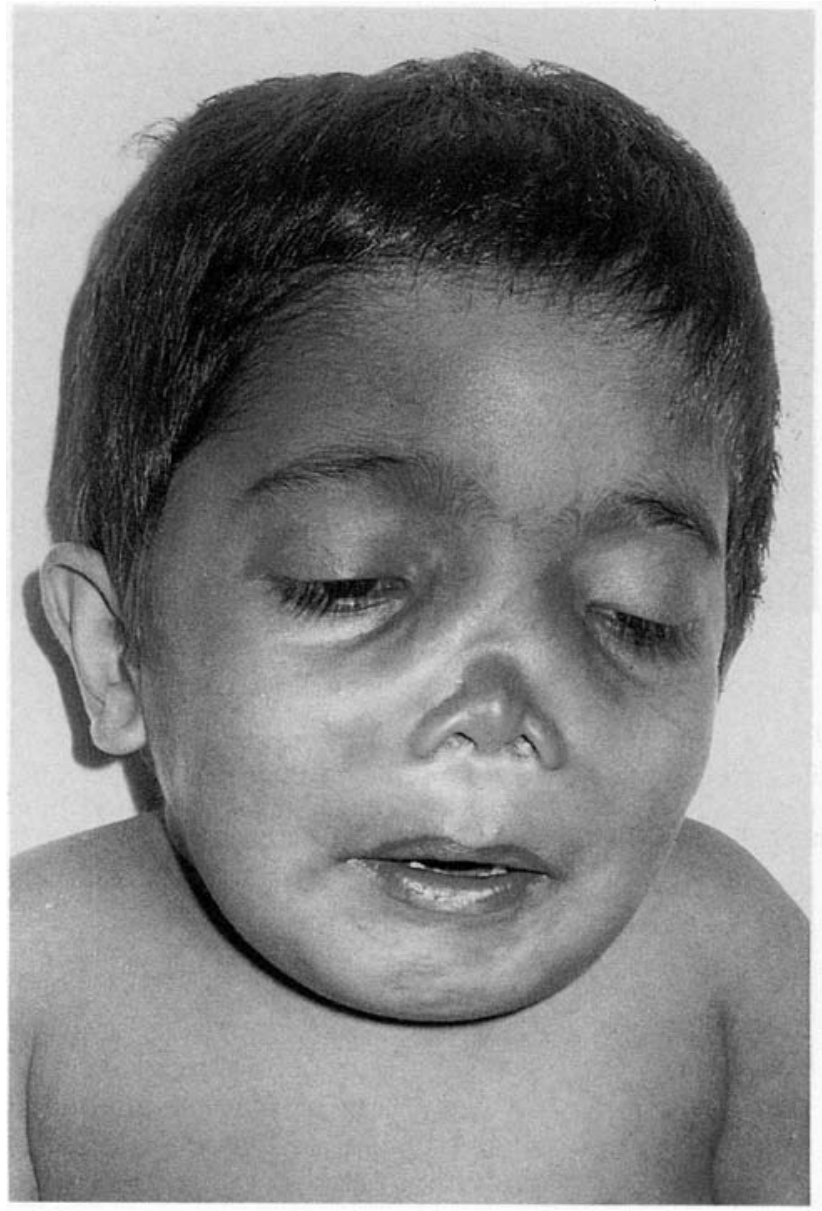

(a)

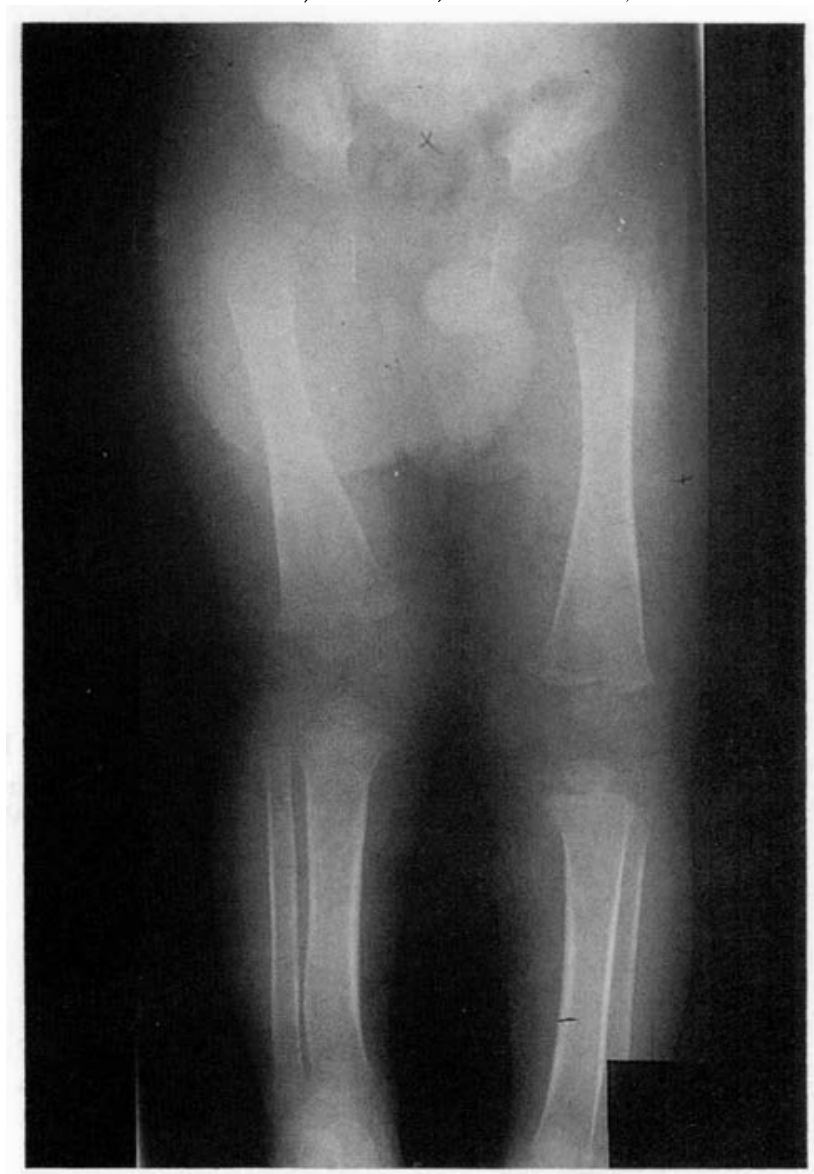

(c)

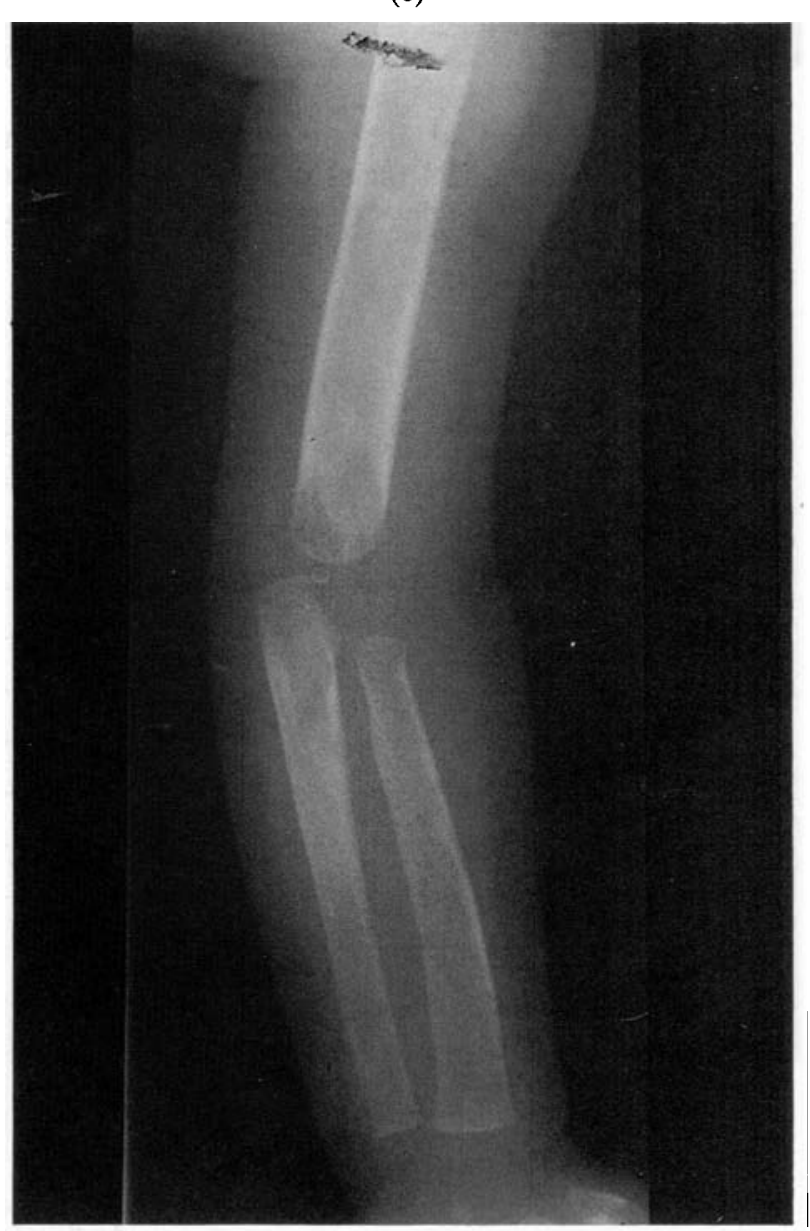

(d) 


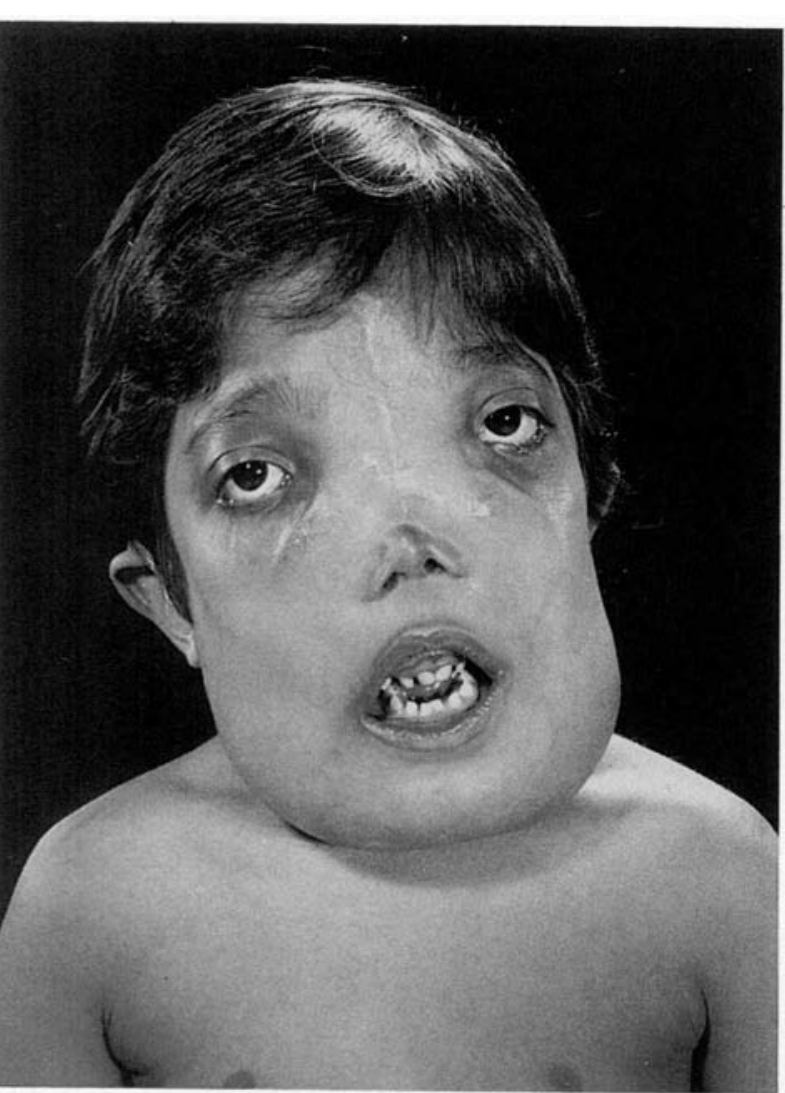

(e)

age, mini-Shah grommets were inserted. At surgery, the tympanic membranes were retracted onto the promontories, and no ossicles were observed in the rudimentary tympanic cavities. Re-insertion of grommets a year later was not possible due to gross retraction of the tympanic membranes and narrow external auditory meati. At 18 months of age, he had bilateral epiphora and no upward ocular gaze. At three and a half years, surgery was performed to improve his facial appearance. The extremely thick and sclerotic nasal bones and maxilla were recontoured by a craniofacial approach using an oscillating saw and osteotome. This proved extremely difficult as the bone was ivory hard. Six weeks post-operatively, there was complete recurrence of the bony overgrowth of both maxillae and nasal bones (Figure 3e).

His serum and urine biochemistry were normal apart from a raised serum alkaline phosphatase. He received calcitriol with a low calcium diet for a year with no evidence of increased serum calcium or raised urinary calcium/creatinine ratios. His alkaline phosphatase remained consistently elevated. His clinical condition continued to worsen with deterioration of his hearing (Figure 4) and vision. A CT scan found encroachment by bony sclerosis which narrowed the optic foramina, facial nerve canal, middle ear cavity, as well as the internal and external auditory canals but the cochlea and semicircular canals appeared normal (Figure 3f). After unsuccessful trials of dexamethasone and heparin, he commenced treatment with somatostatin after a bone biopsy double-labelled by tetracycline

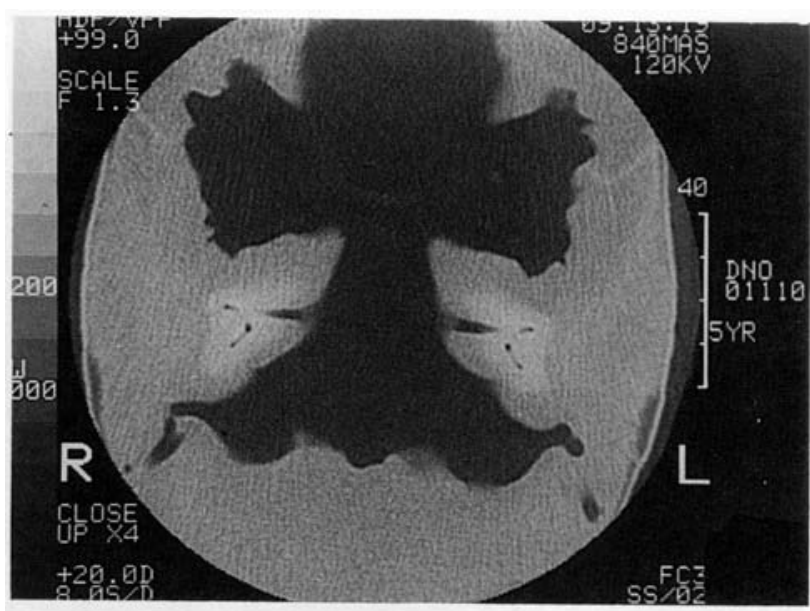

(f)

FIG. 3

Case 2 (a) Facial appearance age one year (b) Plain chest Xray-note midclavicular hyperostosis and widened ribs. (c) Plain X-ray of femur, tibia and fibula (d) Plain X-ray of humerus, radius and ulna. Note diaphyseal endostosis and the policeman's truncheon appearance. (e) Facial appearance six weeks after recontouring of nasal bones and maxilla (f) CT scan (1990) of the temporal bone the IAM's appear slightly narrow. The middle ear cavities are encroached upon by bone.

showed increased osteoblasts, and an octreotidelabelled bone scan, performed to see whether the bone cells had octreotide receptors, revealed some uptake of the tracer in the facial bones. At eight years of age, he was learning braille for deaf-blind communication. Severe enlargement of his mandible caused pain secondary to pressure on his clavicles and he wore a collar as his head was too heavy to support. His bite became increasingly malaligned, he found eating difficult and he dribbled much of the time. A palliative jaw resection was performed using a Midas Rex diamond drill. The operation required eight hours and 12 drill bits to remove $1 / 2 \mathrm{~kg}$ of bone. He died suddenly by arresting in the playground at school earlier this year. Although no post mortem was performed, it has been presumed that acute cord compression occurred.

\section{Case 3}

This girl's facial appearance was noted to be the same as her father's at birth. The diagnosis of craniometaphyseal dysplasia was made at the age of two. She was referred at the age of four for further investigation including prognosis regarding her facial appearance. Her chief complaints were nasal obstruction with recurrent upper respiratory tract infections, snoring, mouthbreathing, recurrent conjunctivitis and hearing loss. On examination, she had hypertelorism, a broad flat nose, nasal obstruction with mouthbreathing, large tonsils, otitis media with effusion and a mild left facial nerve paresis (Figure 5a). An audiogram showed a mild hearing loss 

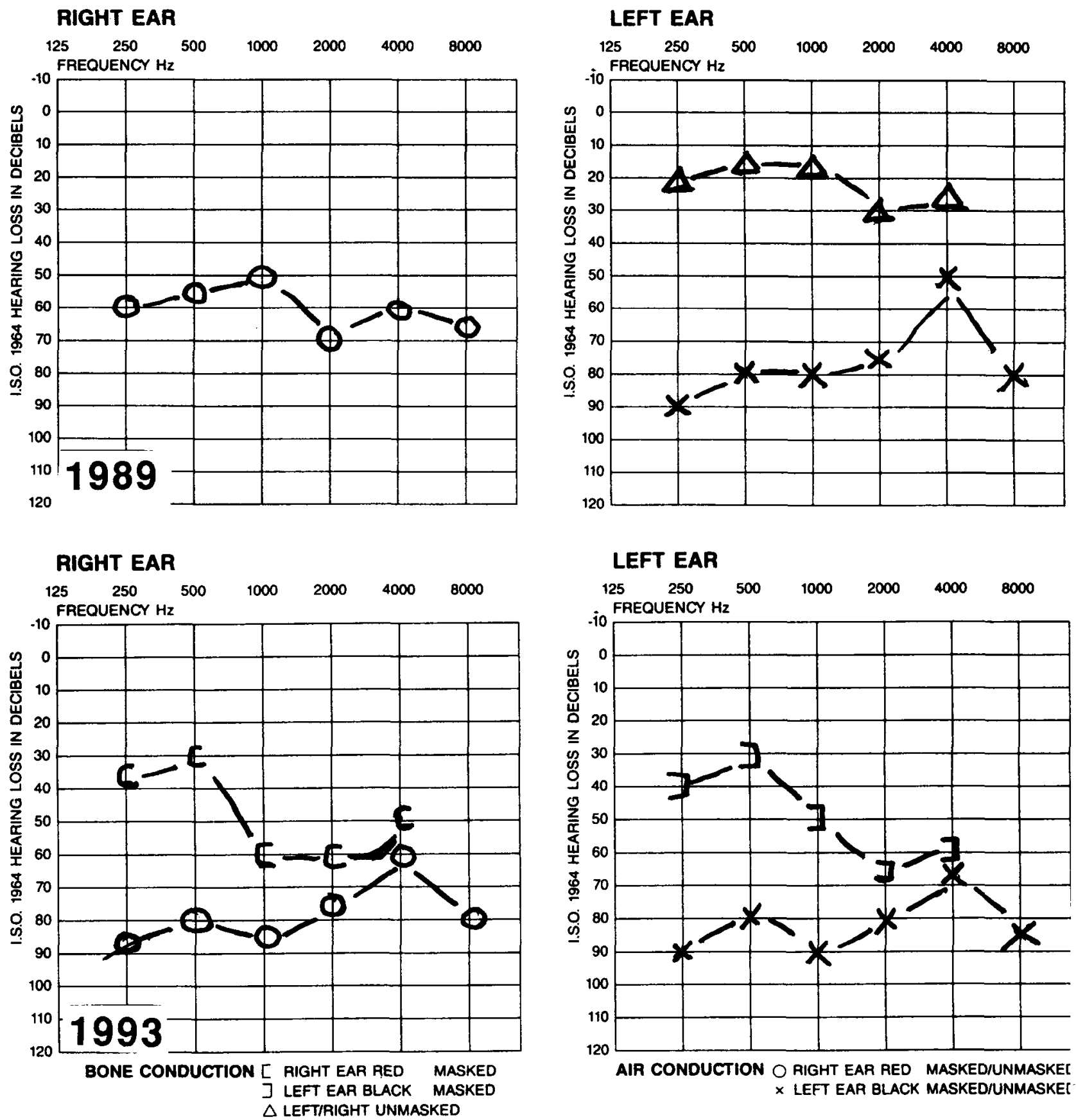

FIG. 4

Audiogram Case 2 (1989 and 1993). Note deterioration from conductive to mixed sensorineural hearing loss.

bilaterally (Figure 6). Skeletal survey found the bony changes of craniometaphyseal dysplasia (Figures 5b, 5c and 5d). Adenotonsillectomy and grommet insertion was undertaken. Post-operatively her hearing and upper airway were improved. Her urine and serum biochemistry were normal apart from a raised alkaline phosphatase $(559 \mathrm{U} / \mathrm{l})$. Calcitriol treatment with a low calcium diet was commenced but unlike the two previous cases with CDD, serum calcium and calcium-creatinine ratios increased and the alkaline phosphatase level returned to normal (211 U/1). After two years, no clinical evidence of bone loss was apparent. Her cranial CT scan was unchanged. There was no evidence of progressive cranial nerve entrapment. The calcitriol and a low calcium diet was stopped. She will continue to have six monthly ophthalmic and ENT review, annual renal ultrasound and a cranial CT to monitor her condition to ensure that it remains stable without treatment.

\section{Case 4}

The facial appearance of the father of Case 3 as a child was similar to that of his daughter but it gradually improved during childhood and adolescence. He has never undergone any surgery. He has not been troubled by epiphora, facial palsy, nasal 


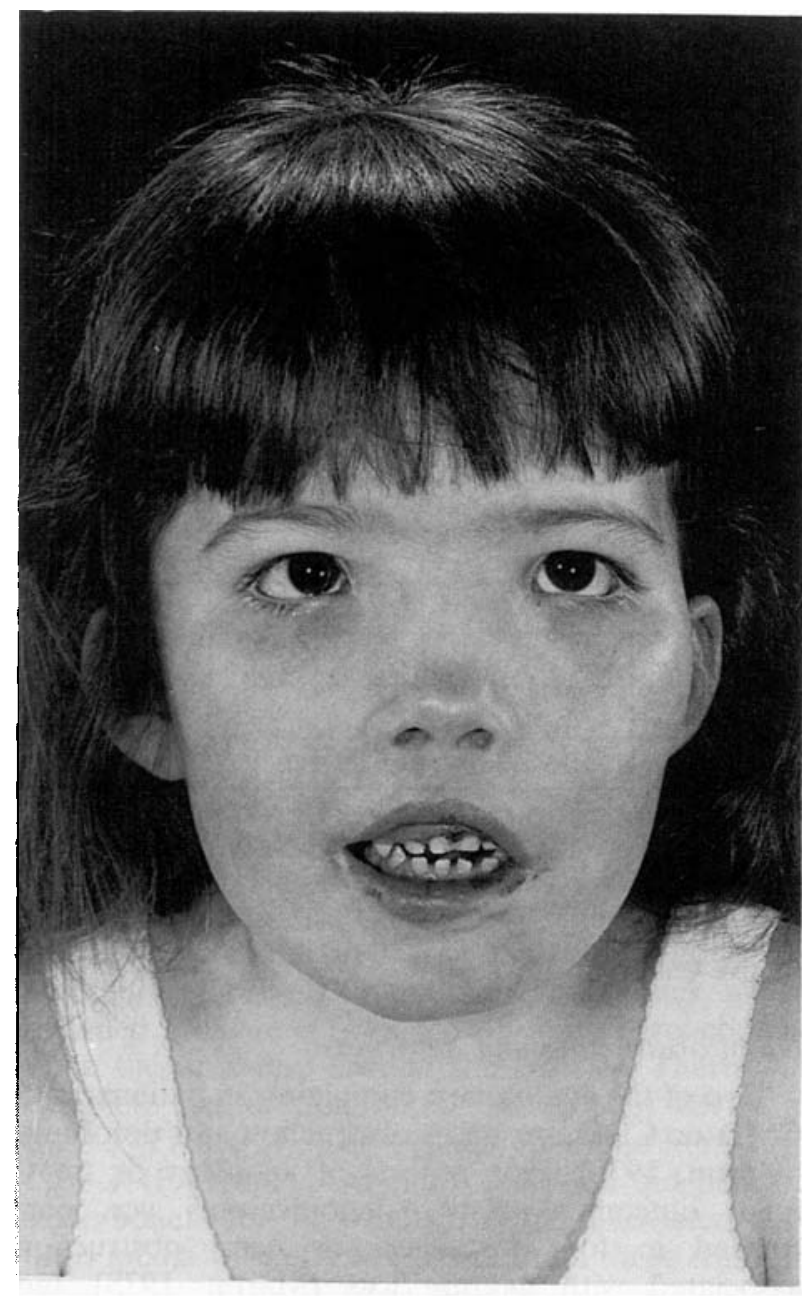

(a)

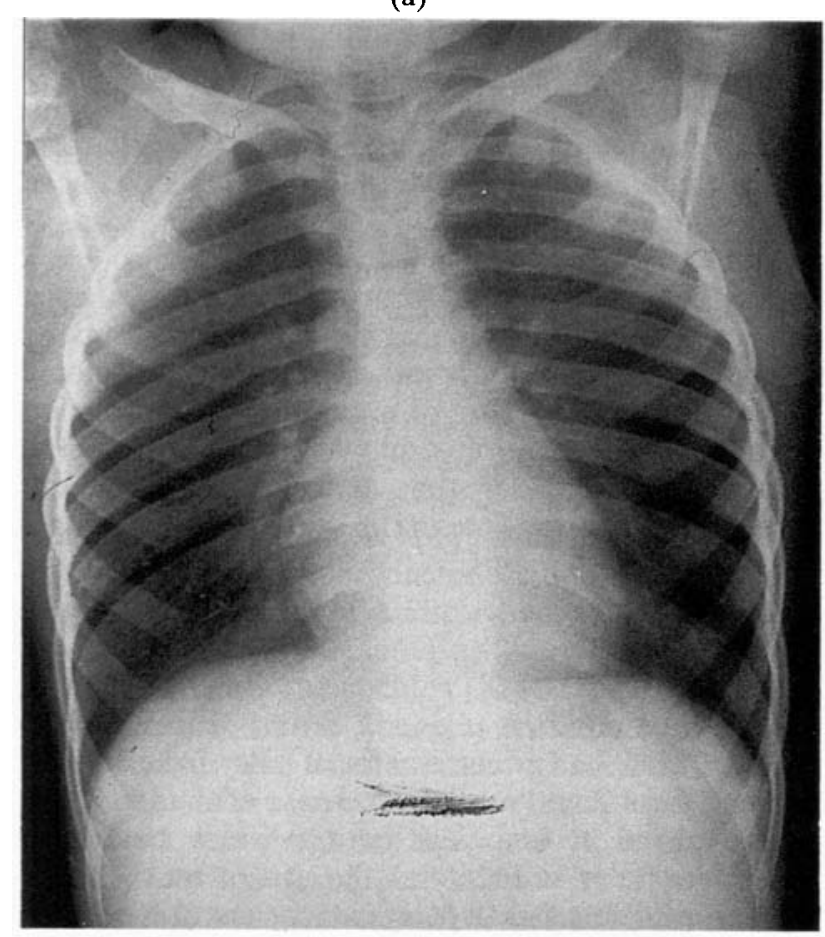

(b)

Fig. 5

Case 3 age five years (a) Facial appearance. (b) Plain chest Xray (midclavicular hyperostosis and sclerosis has resolved). (c) Plain X-ray of femur with narrow diaphysis and widened metaphysis "Erhlenmeyer flask" appearance. (d) Plain X-ray of mandible (e) CT scan including temporal bones (1991).

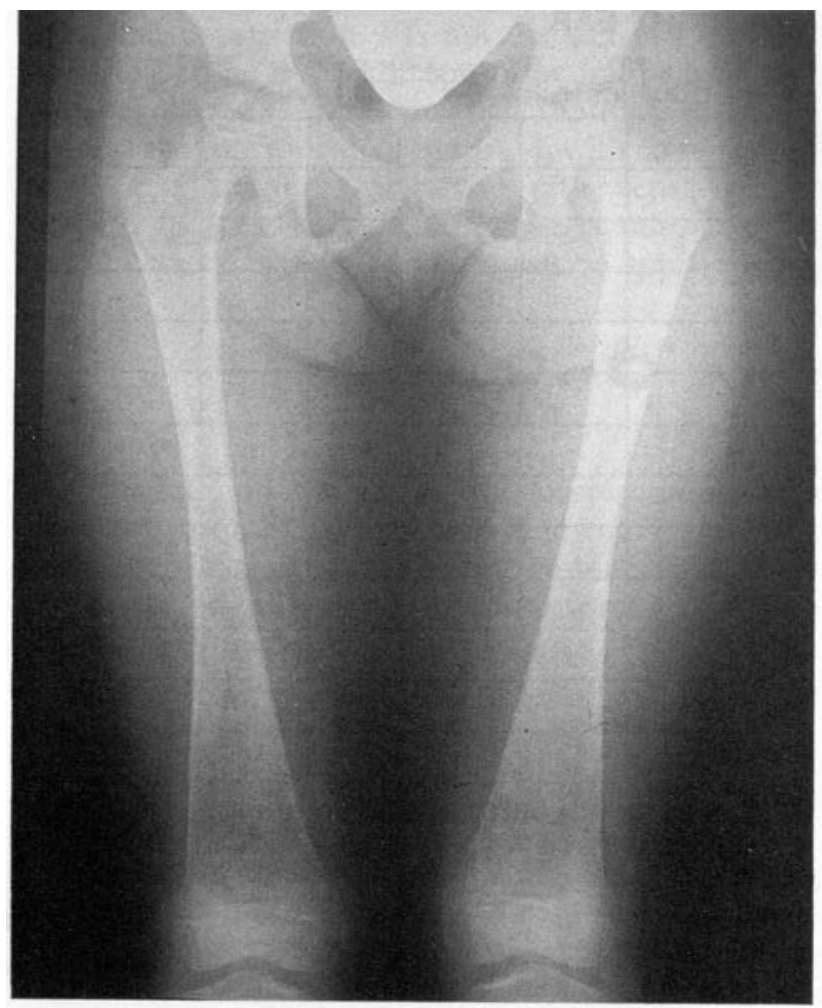

(c)

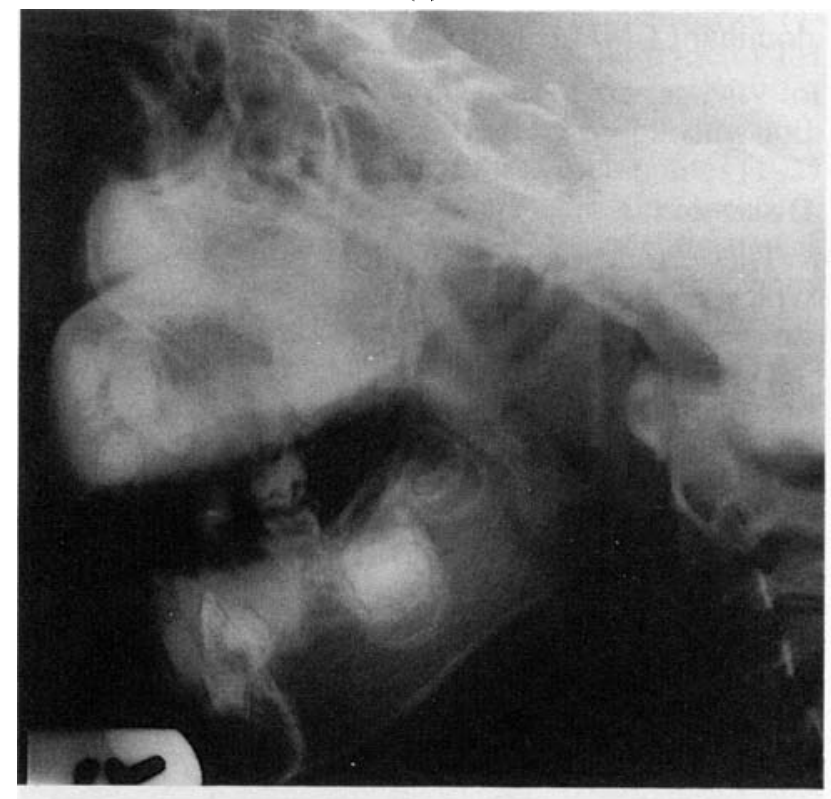

(d)

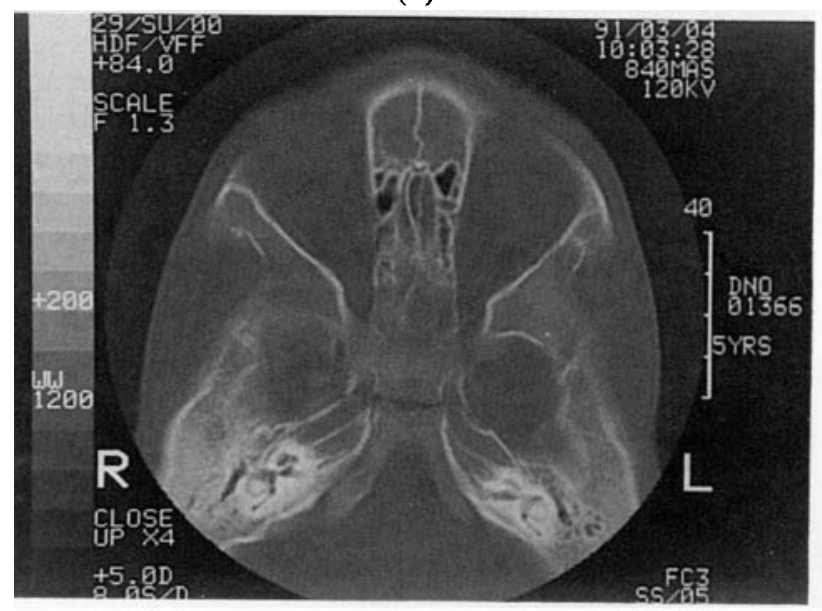

(e) 


\section{RIGHT EAR}

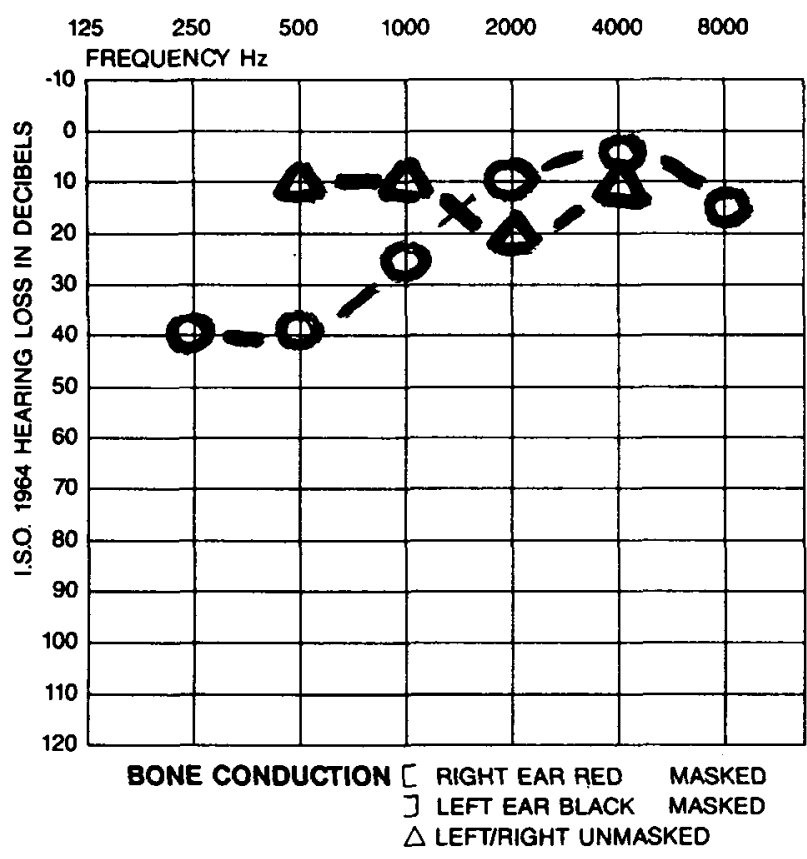
LEFT EAR

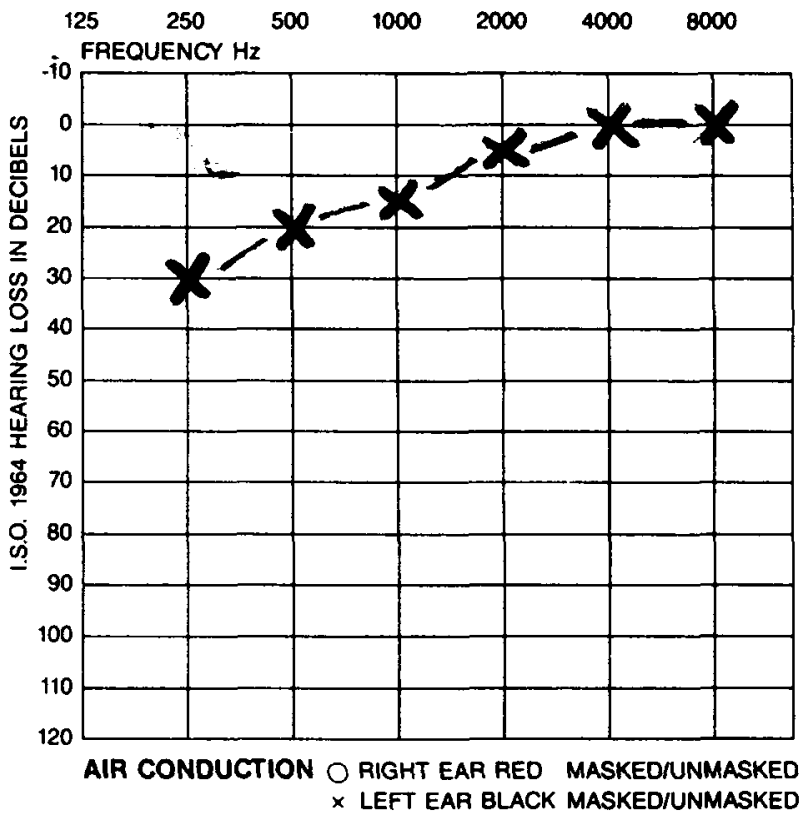

FIG. 6

Audiogram Case 3 age five years.

obstruction or hearing loss. They have autosomal dominant CMD (Figure 7).

\section{Discussion}

These four patients demonstrate many of the typical craniofacial abnormalities and clinical features for which these syndromes are known, including progressive bony facial deformity, nasal obstruction and deformity, facial palsy, epiphora, malocclusion, deafness and blindness.

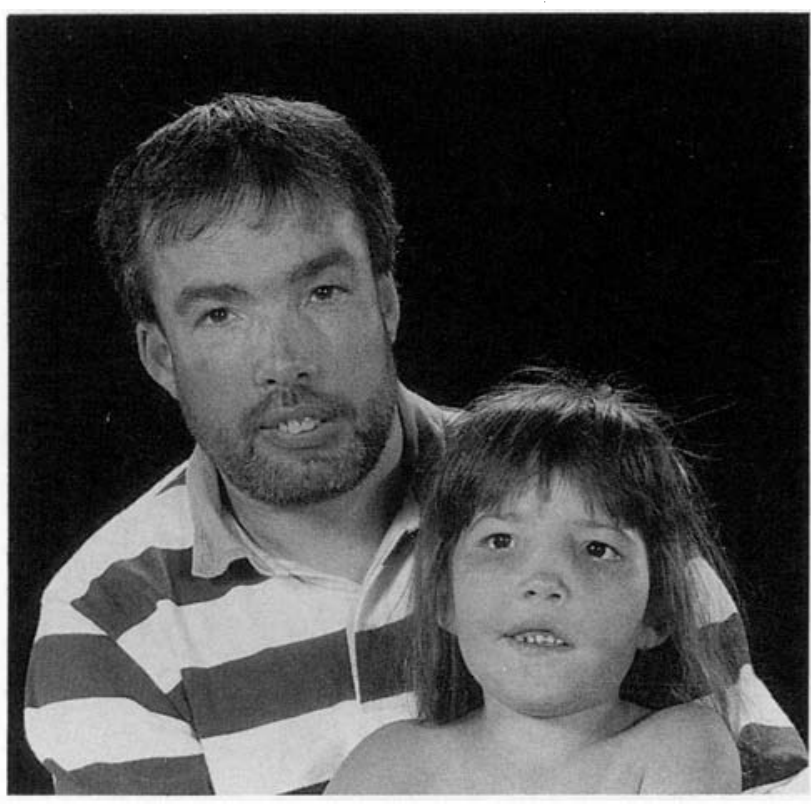

Fig. 7

Father and daughter (Cases 4 and 3).

\section{Nasal obstruction and deformity}

Two of the commonest complaints in patients with CMD or CDD are nasal obstruction and deformity (Martin, 1978). Few reports of aetiology or treatment outcomes exist. Adenoidectomy was performed in four instances for nasal obstruction associated with hearing loss (Martin, 1978) and choanal stenosis has been treated surgically, all without a mention of outcome (Kietzer and Paparella, 1969). Three cases have had unsuccessful rhinoplasties in which nasal obstruction and deformity remained a persistent problem (Macpherson, 1974; Shea et al., 1981; Morgan et al., 1990). Facial recontouring for cosmetic deformity in Case 2 resulted in bony regrowth by six weeks postoperatively. Regrowth occurred so rapidly that it was considered possible that surgery stimulated bone growth. Case 3 underwent an adenotonsillectomy with symptomatic relief of upper airway obstruction which was not entirely due to bony obstruction, which is a reminder that conventional treatment continues to have a role in the symptomatic management of these patients.

\section{Facial nerve}

All three children (Cases 1,2 and 3) had a facial palsy. Case 2 had a bilateral facial palsy from 10 days of age, Case 1 had a mild weakness of the left facial nerve noted at one year of age which became a complete palsy suddenly at the age of four. Case 3 had a mild left facial palsy which has not deteriorated further. It has been presumed that a disturbance of facial nerve function develops from bony encroachment upon the facial nerve along its course in the temporal bone. The exact mechanism and topographical site giving rise to a facial palsy has not 
been previously determined. From the CT scans we can see that the facial canal is narrowed at the geniculate ganglion (Figure 1e). Facial nerve decompression has never been reported. We do not recommend it as the benefits are likely to be shortlived and the technical difficulties and risks enormous (with a sclerotic mastoid, ivory-hard bone and all landmarks obscured by bony overgrowth to deal with). Optic nerve decompression has been reported to be technically difficult with restenosis of the optic canals after three years in one report and a reduction in vision after attempted decompression in another (Puliafito et al., 1981).

\section{Otological findings}

Previous reports describing gross hyperostotic changes of the annulus and promontory, a markedly constricted additus and attic, the ossicles enveloped, and the Eustachian tube and both labyrinthine windows obstructed by bony overgrowth (Kietzer and Paparella, 1969; Shea et al., 1981; Morgan et al., 1990) are consistent with ours. The conductive hearing loss found in Cases 1,2 and 3 could be accounted for by the middle ear findings which included gross bony overgrowth and encroachment upon the attic and around the ossicles. There was complete obliteration of the middle ear cavity in Case 2 (Figure 3f). The ossicles appeared normal in Case 1 (Figure 1). Grommet insertion did provide some benefit for the conductive loss associated with otitis media with effusion found in all three children at an early stage. Narrow external auditory canals may prevent further grommet insertion as occurred in Case 2. Shea et al. (1981) performed a stapedectomy and total ossicular replacement graft for a stapes which was fixed in the oval window by bone with an improvement in the conductive hearing loss. How long the hearing result lasted is unreported. Given the natural history of progression of bony overgrowth and the possibility that surgery stimulates this in CDD, a bone anchored hearing-aid for a conductive loss (as in Case 1) has been dismissed due to the risk that bone may overgrow the bone anchored implant fixture and/or the final abutment.

The aetiology of the sensorineural hearing loss which develops in severe CMD and in CDD has not been identified before. Three mechanisms have been suggested: 1) bony encroachment upon the auditory nerve in the internal auditory canal; 2) extensive bony closure of both labyrinthine windows; and 3) bony invasion of the cochlea (Kietzer and Paparella, 1969). We noted no abnormalities in the cochlear structures in any of our cases on their CT scans. Narrowing of the internal auditory meati was present in Cases 1 and 2 but not in Case 3. A sensorineural hearing loss has developed only in Case 2 to date. It is known, however, that the IAM can be very narrow in association with normal hearing if the constriction occurs slowly, allowing for compensation in the blood supply (Dr P. D. Phelps, personal communication). A fourth possible aetiology is disruption of the flow of cochlear fluids. However, cochlear aqueduct constriction was not evident in CT scans of Case 2 when a marked sensorineural hearing loss had developed. Hence, most of the evidence does suggest that narrowing of the IAM, with compromise of the auditory nerve, gives rise to the sensorineural hearing loss associated with these syndromes. As such, a cochlear implant would not be appropriate.

\section{Epiphora}

Syringing and probing of the nasolacrimal ducts was not useful. Dacryocystorhinostomy provided some symptomatic benefit, but restenosis is likely to occur in the more severe forms of these syndromes (as in Case 1).

\section{Medical management}

As long as the underlying bone modelling defect(s) in these disorders remains largely unexplained, medical therapy will be experimental. The regulation of bone turnover and hence the maintenance of calcium balance and homoeostasis involves parathyroid hormone (PTH), calcitriol (1$25(\mathrm{OH})_{2}$ Vit $\left.\mathrm{D}_{3}\right)$ and calcitonin. In bone, PTH increases the number and osteolytic activity of osteoclasts and osteocytes, thereby mobilizing both calcium and phosphate. Vitamin D metabolites (1-25 $(\mathrm{OH})_{2}$ Vit $\left.\mathrm{D}_{3}\right)$ are necessary for this process. Treatment with calcitriol and a low calcium diet is suggested to be effective in depleting the bony skeleton with the risk of hypocalcaemia, decalcifying the normal skeleton, and nephrocalcinosis. However, calcitriol has been found to stimulate osteoclastic resorption in osteopetrosis without producing hypercalcaemia if dietary calcium was severely restricted (Key et al., 1988). Calcitriol stimulates the resorption of bone by promoting recruitment and differentiation of monocytic precursors to form multinucleated osteoclasts on actively remodelling bone surfaces (Roodman et al., 1985). On the basis that net bone formation would be diminishing using calcitriol and a low calcium diet, this treatment was commenced in all three children. The low calcium diet was to prevent further deposition of mineral in bone and allow the calcitriol-induced osteoclasts to reduce the skull bone mass. In CMD (Case 3) the urine calcium/ creatinine ratios were intermittently raised suggesting that there was some mobilization of mineral from bone as a result of calcitriol treatment. In CDD (Cases 1 and 2) calcitriol in conjunction with a low calcium diet caused no appreciable increase in the urine calcium-creatinine ratio and no change in serum calcium levels. Once this treatment had been used in Cases 1 and 2 with no appreciable arrest of progression of bony growth over a period of more than two years, alternative therapies were sought. Bone biopsy histopathology has found increased numbers of osteoblasts. Hence, therapy directed at the osteoblasts was sought and is now under trial. 


\section{Conclusion}

Nasal obstruction with choanal stenosis is often the earliest presenting complaint in these rare syndromes. The hearing abnormality appears to progress from a conductive to a mixed sensorineural loss in CDD. We found both middle ear and IAM abnormalities exist in CDD. Surgical intervention in these conditions is palliative, technically difficult due to the ivory-hard bone and the benefits are shortlived. The underlying pathophysiological abnormality is yet to be fully understood. The aim of medical treatment is to disrupt the underlying bone disorder. Arresting net bone growth in the early stages would avert the devastating consequences in the severe forms of CMD and CDD. Early diagnosis is crucial to allow early commencement of medical therapy as well as appraisal of likely prognosis and surgical outcomes.

\section{Acknowledgements}

We are grateful to Dr Susan Bellman for the audiological assessments, Dr Christine Hall for her radiological assessments and Dr Peter Phelps for the CT scan assessments.

\section{References}

Bonucci, E., Menichini, G., Scarfo, G. B., Tonaccini, D. (1977) Histologic, microradiographic and electron microscopic investigations of bone tissue in a case of craniodiaphyseal dysplasia. Virchows Archiv für Pathologische Anatomie 373: $167-175$.

Cole, D. E., Cohen, M. M. Jr. (1988) A new look at craniometaphyseal dysplasia. Journal of Pediatrics 112(4): 577-579.

Fanconi, S., Fischer, J. A., Wieland, P., Giedion, A., Boltshauser, E., Olah, A. J., Landolt, A. M., Prader, A (1988) Craniometaphyseal dysplasia with increased bone turnover and secondary hyperparathyroidism: Therapeutic effect of calcitonin. Journal of Pediatrics 112(4): 587-590.

Gorlin, R. J., Spranger, J., Koszalka, M. F. (1969) Genetic craniotubular bone dysplasias and hyperostoses. A critical analysis. Birth Defects 5(4): 79-95.

Gorlin, R. J., Cohen, N. M., Levin, L. S. (1990) Syndromes of the Head and Neck: Craniotubular Bone Disorders. 3rd Edition, Oxford University Press, New York, 229-231.

Greenspan, A. (1991) Sclerosing bone dysplasias-a target site approach. Skeletal Radiology 20(8): 561-583.

Halliday, J. (1949) A rare case of bone dysplasia. British Journal of Surgery 37: 52-63.

Jackson, W. P. U., Albright, F., Dewry, G., Hanelin, J., Rubin, M. I. (1954) Metaphyseal dysplasia, epiphyseal dysplasia, diaphyseal dysplasia and related conditions. Archives of Internal Medicine 94: 871-885.

Joseph, R., Lefebvre, J., Guy, E., Job, J. C. (1958) Dysplasie cranio-diaphysaire progressive: Ses relations avec la dysplasie progressive de camurati-Engelman. Annals of Radiology 1: 477-490.
Kaitila, I., Stewart, R. E., Landow, E., Lachman, R., Rimoin, D. L. (1975) Craniodiaphyseal dysplasia. Birth Defects 11(6): $359-361$.

Key, L. L. Jr., Volberg, F., Baron, R., Anast, C. S. (1988) Treatment of craniometaphyseal dysplasia with high dose calcitriol. Journal of Pediatrics 112(4): 583-586.

Kietzer, G., Paparella, M. M. (1969) Otolaryngological disorders in craniometaphyseal dysplasia. Laryngoscope 79(5): 921-941.

Levy, M. H., Kozlowski, K. (1987) Cranio-diaphyseal dysplasia. Australasian Radiology 31: 431-435.

Macpherson, R. I. (1974) Craniodiaphyseal dysplasia, a disease or group of diseases? (Case 1). Journal de L'Association Canadienne des Radiologistes 25(1): 22-23.

Martin, F. W. (1978) Otorhinolaryngological aspects of craniometaphyseal dysplasia. Clinical Otolaryngology 4: 67-76.

Millard, D. R., Maisels, D. O., Batstone, J. H., Yates, B. W. (1967) Craniofacial surgery in craniometaphyseal dysplasia. American Journal of Surgery 113(5): 615-612.

Morgan, D. W., Aldren, C., Hoare, T. J. (1990) Hearing loss due to cranio-metaphyseal dysplasia. Journal of Laryngology and Otology 104: 807-808.

Munro, I. R., Lauritzen, C. G., Hoffman, H. J., Sinclair, W. J. (1983) Craniometaphyseal Dysplasia-Correction of a Giant Head. (Williams, H. B., ed), Transactions of the Eighth International Congress of Plastic and Reconstructive Surgery, McGill University Press, Montreal, pp 323-325.

Puliafito, C. A., Wray, S. H., Murray, J. E., Boger, W. P. (1981) Optic atrophy and visual loss in craniometaphyseal dysplasia. American Journal of Ophthalmology 92(5): 696-701.

Roodman, G. D., Ibbotson, K. J., MacDonald, B. R., Kuehl, T. J., Mundy, G. R. (1985) 1, 25-Dihydroxyvitamin $D_{3}$ causes formation of multinucleated cells with several osteoclast characteristics in cultures of primate marrow. Proceedings of the National Academy of Sciences USA 82: 8213-8217.

Rubin, P. (1964) Dynamic Classification of Bone Dysplasias. Year Book Publishers, Chicago, USA p 410.

Shafer, B. M., Hall, C. M., Jones, B. M. (1990) Craniometaphyseal and diaphyseal dysplasia: diagnosis and challenges in craniofacial surgery (presented at the European Association of Plastic Surgeons, 1991 Spain). (unpublished).

Shea, J., Gerbe, R., Ayani, N. (1981) Craniometaphyseal dysplasia: the first successful surgical treatment for associated hearing loss. Laryngoscope 91(8): 1369-1374.

Yamamoto, T., Kurihara, N., Yamaoka, K., Ozono, K., Okada, M., Yamamoto, K., Matsumoto, S., Michigami, T., Ono, J., Okada, S. (1993) Bone marrow-derived osteoclastlike cells from a patient with craniometaphyseal dysplasia lack expression of osteoclast-reactive vacuolar proton pump. Journal of Clinical Investigation 91(1): 362-367.

Address for correspondence:

Miss Aurelia Richards, F.R.C.S.,

Department of Otolaryngology,

Guy's Hospital,

St Thomas' Street,

London SE1 9RT.

Tax: 0171-955-8878 